\title{
Assessment of subcutaneous glucose concentration: validation of the wick technique as a reference for implanted electrochemical sensors in normal and diabetic dogs
}

\author{
U.Fischer ${ }^{1}$, R. Ertle ${ }^{1}$, P. Abel ${ }^{1}$, K. Rebrin ${ }^{1}$, E. Brunstein ${ }^{1}$, H.Hahn von Dorsche ${ }^{2}$ and E. J.Freyse ${ }^{1}$ \\ ${ }^{1}$ Central Institute of Diabetes "Gerhardt Katsch", Karlsburg and \\ ${ }^{2}$ Department of Anatomy, Ernst Moritz Arndt University, Greifswald, German Democratic Republic
}

\begin{abstract}
Summary. Employing saline-impregnated cotton threads, an implanted-wick technique was adopted in dogs to obtain specimen from the subcutaneous interstitial compartment in order to estimate its glucose concentration. By measuring the protein, potassium and haemoglobin contents, the centrifuged wick fluid was shown to contain the interstitial concentration of solutes after an equilibration time of approximately $15 \mathrm{~min}$. In normal and in diabetic animals the steady state subcutaneous glucose concentration was almost identical to the circulating glucose level when ranged between 2 and $25 \mathrm{mmol} / \mathrm{l}$. Slow alterations in the circulating glucose profile such as those which appear during an oral glucose tolerance test are closely mirrored by the respective levels in the wick fluid. Fast alterations, however, show deviations.
\end{abstract}

The wick-based glucose levels are well paralleled by the current of Clark type glucose oxidase sensors implanted at the same site. Since, on the basis of in vitro calibrations the sensor outputs have only indicated apparent tissue glucose concentrations of between 70 and $90 \%$ of glycaemia, another reference is needed for calibration. Under steady state conditions, the wick method, and on this basis in routine measurements the blood glucose concentration, may be recommended as a reference of implanted sensors which can otherwise not be calibrated in situ.

Key words: Subcutaneous glucose concentration, wick technique, enzyme sensor.
At present, research towards intracorporal glucose sensors is mainly focussed upon subcutaneous implanted electrodes [1-3]. There is, however, no verification of the output of such sensors as a measure of the true interstitial glucose concentration because in situ verification is still impossible. Thus, data reported in the literature employing enzymatic glucose sensors [4-8] show apparent subcutaneous glucose concentrations of between 20 and $85 \%$ of glycaemia. This is in contrast to acknowledged models of microcirculation and mass exchange across the capillary wall [9-11]. In addition, an appropriate reference is needed for checking implanted sensors because of their zero shift and because of alterations in sensitivity, which are still crucial points [5, 12].

There have been reports that lymph fluid may be a reliable sample of extravascular extracellular (i. e. interstitial) fluid which applies to glucose [11] and to insulin [13]. However, lymph sampling does not appear easy to perform in repeated serial experiments. Attempts to directly obtain substantial amounts of interstitial [14] or peritoneal fluid [15] or of aqueous humor of the eye $[16,17]$ for analytical purposes using implanted devices have also failed to solve this problem. These attempts have mostly led to the induction of inflammatory reactions and they did not allow reproducible serial samplings. The problem of obtaining analytical fluid may, however, be reduced to the equilibration of a concentration gradient between the interstitial space and an analytical compartment which consists of a wet wick as described for the first time by Scholander et al. [18] and confirmed by Aukland et al. [19] and Johnsen [20]. Employing this technique, serially repeated analyses become possible in order to follow kinetic patterns and to check the reliability of other devices implanted at the same site. This paper shows that the wick technique may be reliable for subcutaneous glucose measurements and appropriate as a reference for electrochemical sensors.

\section{Materials and methods}

The experimental animals were 6 conscious healthy Alsatian dogs of both sexes (age $43 \pm 10$ months, body weight $28.4 \pm 1.8 \mathrm{~kg}$ ) and 5 chronically diabetic animals (age $40 \pm 4$ months, duration of diabetes 
$12 \pm 5$ months, body weight $24.8 \pm 1.9 \mathrm{~kg}$ ). Diabetes was produced by subtotal pancreatectomy in combination with an intrasurgical injection of $2 \mathrm{mg} / \mathrm{kg}$ streptozotocin into the artery supplying the remaining part of the pancreas. This procedure and animal handling and characteristics have been detailed elsewhere [21]. The experiments were performed $16-20 \mathrm{~h}$ after the last meal and $1 \mathrm{~h}$ after an intramuscular injection of the sedating agent Combelene (Bayer, Leverkusen, FRG). The diabetic animals were given half of their usual subcutaneous morning dose of insulin (daily requirement $1.52 \pm 0.04 \mathrm{IU} / \mathrm{kg}$ ). They were instrumented with the following: plastic cannulas (Flexüle no.1, VEB Medizinplaste, Lichtenberg, GDR) in an upper leg vein; a subcutaneous set of wicks as described below; an enzymatic glucose sensor implanted at the same site (only in the indicated part of the study); - and - where needed - a lower caval venous infusion catheter (Portex, Hythe, Kent, UK) as inserted through a saphenous vein. Simultaneous measurements of glucose concentration in peripheral venous plasma and in centrifuged wick fluid and of the sensor current were taken under the following conditions:

1. in the fasting state $1,3,5,7,10,15,20,30$ and 60 min after implantation of a set of wicks (without electrochemical sensor) in nor$\mathrm{mal}$ and in diabetic dogs,

2. before and after oral administration of $1.0 \mathrm{~g} / \mathrm{kg}$ glucose, and

3. before, during and after intravenous infusions of insulin followed by a glucose injection or of glucose alone.

The glucose and insulin tests were performed in non-diabetic animals only.

Wick technique. Double-stranded cotton threads (Perlgarn/Baumwolle-echtfarbig, VEB Vereinigte Baumwollspinnereien und Zwirnereien Glauchau, GDR; outer diameter of the dried and relaxed threads 0.8 to $1.0 \mathrm{~mm}$ ) consisting of nearly $100 \%$ cellulose and lignin and phospholipids as minor constituents (manufacturer's information) were cut into pieces of appropriate length and sterilised in a paraformaldhyde atmosphere. Five min before implantation they were immersed in $0.154 \mathrm{~m} \mathrm{NaCl}$. After shaving, skin desinfection, and a small intracutaneous local anaesthesia of the entry and exit sites ( $2 \%$ Xylocitin, VEB Jenapharm Jena, GDR), the threads were inserted in the distal neck and in the interscapular region, using a surgical needle. Approximately $10 \mathrm{~cm}$ length of the threads were located subcutaneously in a transversal position. Where several threads were inserted, the distance between them was approximately
$15 \mathrm{~mm}$. After an appropriate interval, the wicks were removed. Fifteen millimetres were cut from each end and the remainder was immediately centrifuged $(8900 \mathrm{~g})$ over $30 \mathrm{~s}$ on a sieve-insert fitted to a Beckman-plastic cup. The resulting fluid sample of between 10 and 20 ul was immediately analysed. All glucose measurements in plasma and in wick fluid were performed on a Beckman Analyzer (Beckman Fullerton, Calif, USA) with a serial coefficient of variation of $1.8 \%$ (standard serum, $8 \mathrm{mmol} / 1$ ).

The time necessary for complete adaptation of glucose concentration in vitro between wet wicks (initial level in the wick fluid $0 \mathrm{mmol} / 1)$ and a $50 \mathrm{~g} / 1$ protein- and $5 \mathrm{mmol} / 1$ glucose-containing solution was $135 \pm 18 \mathrm{~s}(n=10)$. To estimate the kinetics of in situ adaptation between the wick compartment and interstitial fluid, nine threads were inserted during the $2 \mathrm{~min}$ before zero time and were removed at intervals as indicated above. To follow the patterns in tissue glucose concentration after induced alterations, the wicks were inserted at appropriate intervals to allow indwelling times of between 15 and $20 \mathrm{~min}$.

Selected samples of wick fluid and blood plasma were analysed for haemoglobin (standard cyan-haemoglobin method), protein (standard micro-Biuret method) and potassium (Corning 480 Flame Photometer, Corning Medical and Scientific Ltd. Halstead, Essex, UK).

Glucose oxidase electrode. Its preparation, calibration and implantation have already been described extensively [7, 22]. Briefly, glucose oxidase $/ \mathrm{H}_{2} \mathrm{O}_{2}$ sensors were prepared on the basis of Clark-type amperometric electrodes, forming sandwiches of glucose oxidase as immobilised on sepharose $6 \mathrm{~B}[23]$ and of plane membranes from perforated polyethylene (VEB Babychic Finsterwalde, GDR) and from regenerated cellulose (PT 150 Cuprophan $^{\mathrm{R}}$, VEB Gerätewerk Medingen, GDR). The electrode was a bipolar one with a platinum anode and a silver cathode. The set voltage was $650 \mathrm{mV}$. The outer diameter of the prepared sensors was approximately $2.5 \mathrm{~mm}$, their in vitro response time $T_{95}$ to rectangular concentration gradients was less than $90 \mathrm{~s}$, and linearity comprised 0 to $30 \mathrm{mmol} / 1$ glucose. Sensor preparation was performed the day before the experiment. The sensors were implanted at the expected site of wick insertions in a rectangular position to the wick axis. The sensor current was monitored by a seif-constructed wearable amplifying and displaying device. The wick implantations were begun approximately $120 \mathrm{~min}$ after sensor implantation when stable sensor signals had been achieved.

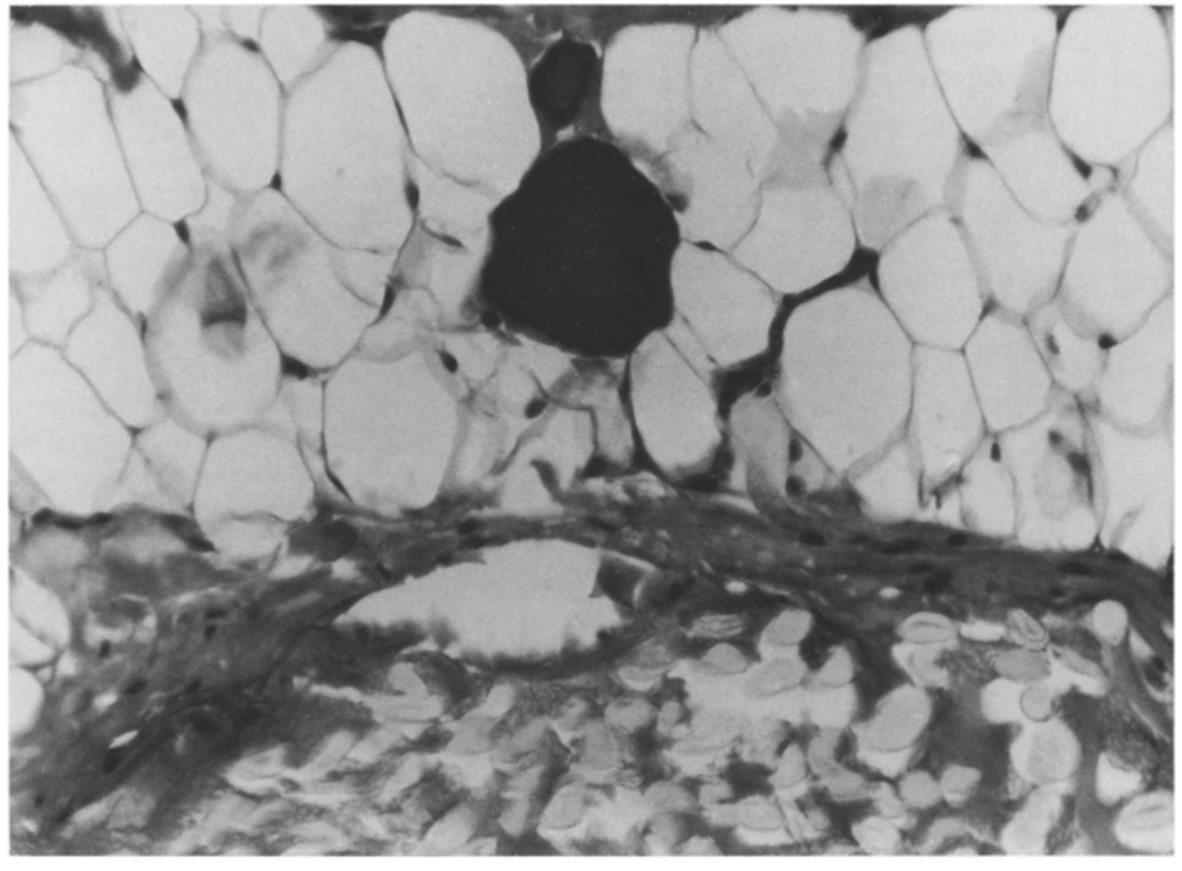

Fig. 1. Histological picture of subcutaneous tissue with a partial wick section (lower third). Note the intact blood vessels and the lack of any appreciable oedema, mononuclear infiltration or cellular detritus. Haematoxylin-eosin, final amplification $\times 670$ 
Immediately before implantation, zero checking and calibration of the sensors was performed in vitro, using glucose solutions of appropriate concentrations dissolved with distilled water and supplemented with $50 \mathrm{~g} / \mathrm{l}$ of human serum albumin. After the experiments, the apparent tissue glucose concentrations were calculated on the basis of the linear parts of the in vitro calibration slopes which were between 0.51 and $5.40 \mathrm{mmol} \cdot 1^{-1} \cdot \mathrm{nA}^{-1}$ in the individual sensor preparations.

Histological examination. Separate studies were performed under general anaesthesia (Pentobarbital, Spofa Praha, CSSR) to obtain biopsy samples. Up to $180 \mathrm{~min}$ after wick implantation, subcutaneous tissue including the threads was excised from the middle of the implantation line. The samples were fixed in Bouin's solution, embedded in paraffin and stained with haematoxylin-eosin.

\section{Statistical analysis}

The means \pm SEM (in the figures + or - SEM) of the data are given. Students' t-test was employed to check statistically significant differences $(p<0.05$ or $<0.01$ respectively).

\section{Results}

More than $180 \mathrm{~min}$ after implantation no pathological alterations could be seen in the tissue surrounding the cotton threads (Fig. 1). Thus neither micro-bleedings nor oedematous or cellular infiltrations could be observed. After wick removal, less than $5 \%$ of the threads were reddish coloured; only these contained haemoglobin $(0.14 \pm 0.11 \mathrm{mmol} / 1, n=18$, as compared to the blood values which were $8.20 \pm 0.21 \mathrm{mmol} / 1, n=10$ in these animals) and they were not taken into account in the rest of the examination. The potassium concentration in the wick compartment was $124.5 \pm 8.8 \%$ of the simultaneous plasma concentration $(n=10, p<0.05)$. Its protein concentration was $58.0 \pm 2.5 \%$ of that in plasma $(n=10, p<0.01)$.

Under basal steady state conditions the glucose concentration in the wick compartment approached that of circulating blood plasma. This concentration was reached $15 \mathrm{~min}$ after implantation without exception and there were no appreciable differences between control and diabetic animals (Fig. 2). This method also proved suitable for analysing the kinetics during an oral glucose tolerance test (OGTT), where the plasma glucose patterns are mirrored by the concentration in the wick fluid (Fig.3). These two curves are closely paralleled by the sensor current and thus by the resulting apparent tissue glucose concentration as estimated on the basis of in vitro calibrations. These values are distinctly lower than those in venous plasma and in the wick samples. Since the in vitro calibration slopes showed a considerable variation between individual sensor preparations the large variability in the sensor current data may easily be explained (Figs.3-5). But there was still a large interindividual variability in some of the sensor-recorded glucose values which points to the importance of a reliable in-situ calibration. In addition, there are deviations both in the wickand sensor-recorded glucose patterns during the initial

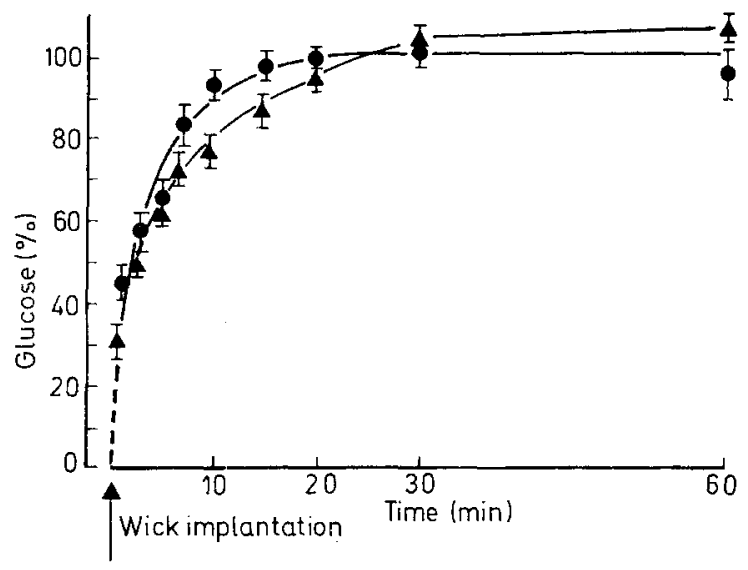

Fig. 2. Kinetics of glucose content in wick fluid, dependent on the duration of implantation in normal (13 experiments on 4 animals, -) and diabetic dogs (10 experiments on 5 animals, $\mathbf{A})$. The values are given as percentages of simultaneously measured blood glucose concentration (mean $\pm \mathrm{SEM}$ ); in the individual experiments $100 \%$ was between 4.5 and $5.7 \mathrm{mmol} / \mathrm{l}$ (non-diabetic dogs) and between 12.7 and $24.0 \mathrm{mmol} / \mathrm{l}$ (diabetic animals)

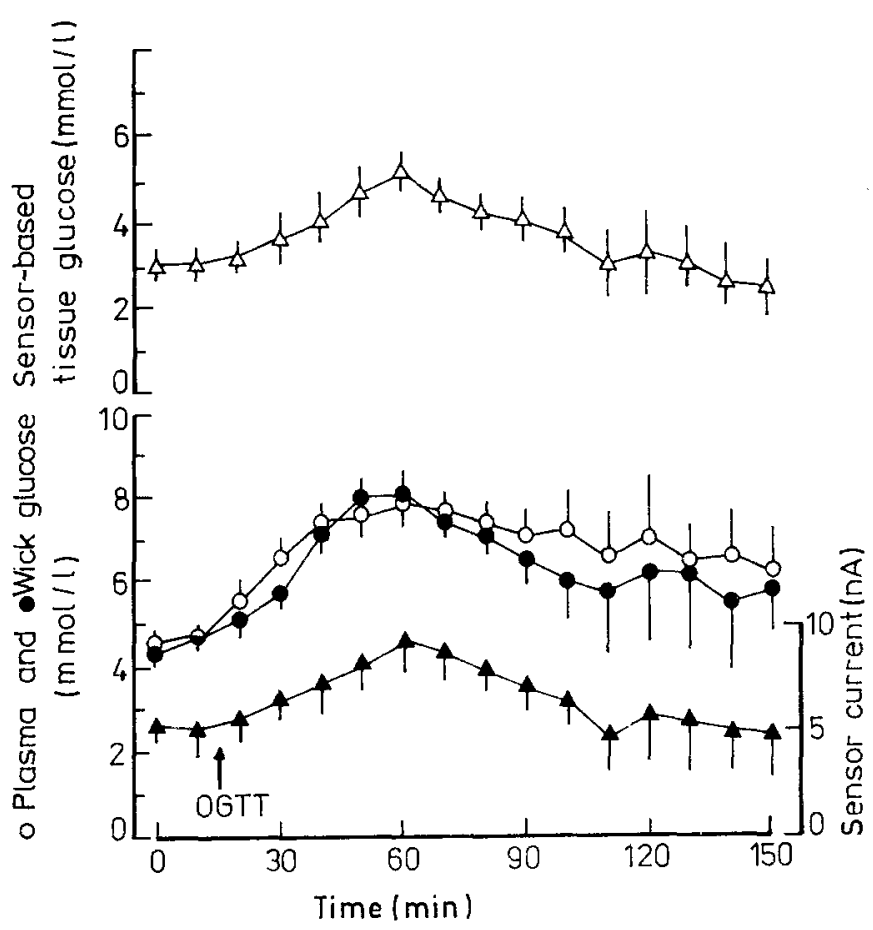

Fig. 3. Glucose concentration in venous plasma and in the wick fluid compartment, and sensor current after an oral glucose load $(1.0 \mathrm{~g} / \mathrm{kg})$. Ten experiments of different duration $(n=5$ from $100 \mathrm{~min}$ and three from $120 \mathrm{~min}$ respectively). $\bigcirc$ - plasma glucose, - wick glucose concentration, $\boldsymbol{A}$ - current of electrochemical sensor taken at intervals from the monitor, $\Delta-$ apparent interstitial glucose concentration estimated from sensor current on the basis of in vitro calibration (upper panel), mean \pm (or + or - ) SEM

fast alterations of circulating glycaemia after intravenous administration of insulin or glucose (Figs. 4 and 5). The delay in the wick and sensor compartments results in distinctly higher or lower glucose levels when glycaemia is rapidly decreasing or increasing respectively. 


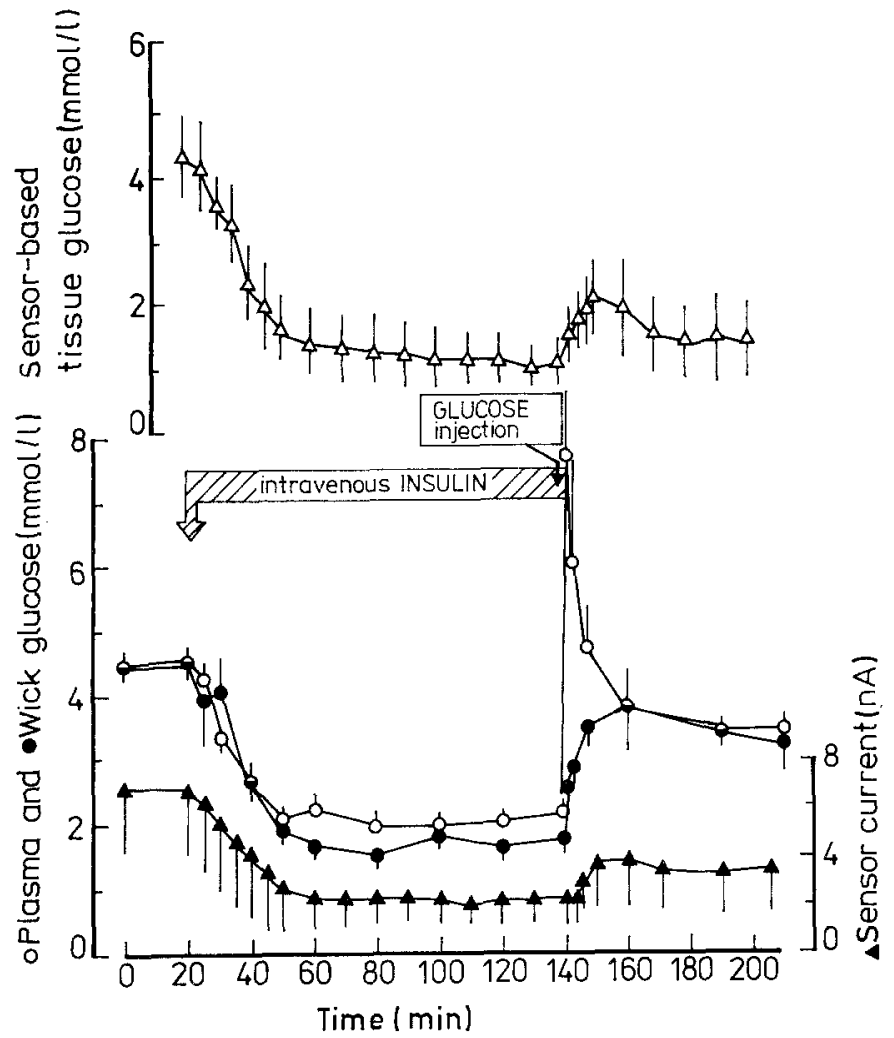

Fig.4. Same measurements and same symbols as in Figure 3 in normal fasting dogs before, during and after intravenous injection of $0.1 \mathrm{IU} / \mathrm{kg}$ and subsequent infusion of $3.0 \mathrm{mU} \cdot \mathrm{kg}^{-1} \cdot \mathrm{min}^{-1}$ of regular porcine monocomponent insulin and injection of $4.0 \mathrm{~g}$ glucose after completion of insulin administration. $n=3$

The latter two studies were mainly undertaken to demonstrate the principle validity of the wick method in the steady state hypo- and hyperglycaemic ranges, too. Under these conditions, i.e. with the exception of the intervals $20-50$ and $140-160 \mathrm{~min}$ of the insulin test (Fig.4) and of the intervals 10-30 and 190-200 min of the glucose infusion (Fig.5), the correlation between the plasma and wick fluid glucose concentrations after the wicks had been in place for $15 \mathrm{~min}$ was $y=0.99 x+0.50$ (81 paired values from 6 experiments as presented in Figures 4 and $5, \bar{y}=9.04$ and $\bar{x}=8.63$ with a range of between 1.5 and $28.0 \mathrm{mmol} / 1, r=0.98$ ). This regression indicates statistically identical glucose concentrations in the intravascular and extravascular parts of extracaellular fluid.

\section{Discussion}

The wick compartment - on implantation - contains the two most important constituents of the extracellular space, i.e. water and saline, thereby providing approximately the normal total osmolality. Thus the only process under consideration is the diffusional equilibration of all solutes which have different concentrations in the wick and in the interstitial tissue fluid compartments. This also applies to glucose, whose tissue

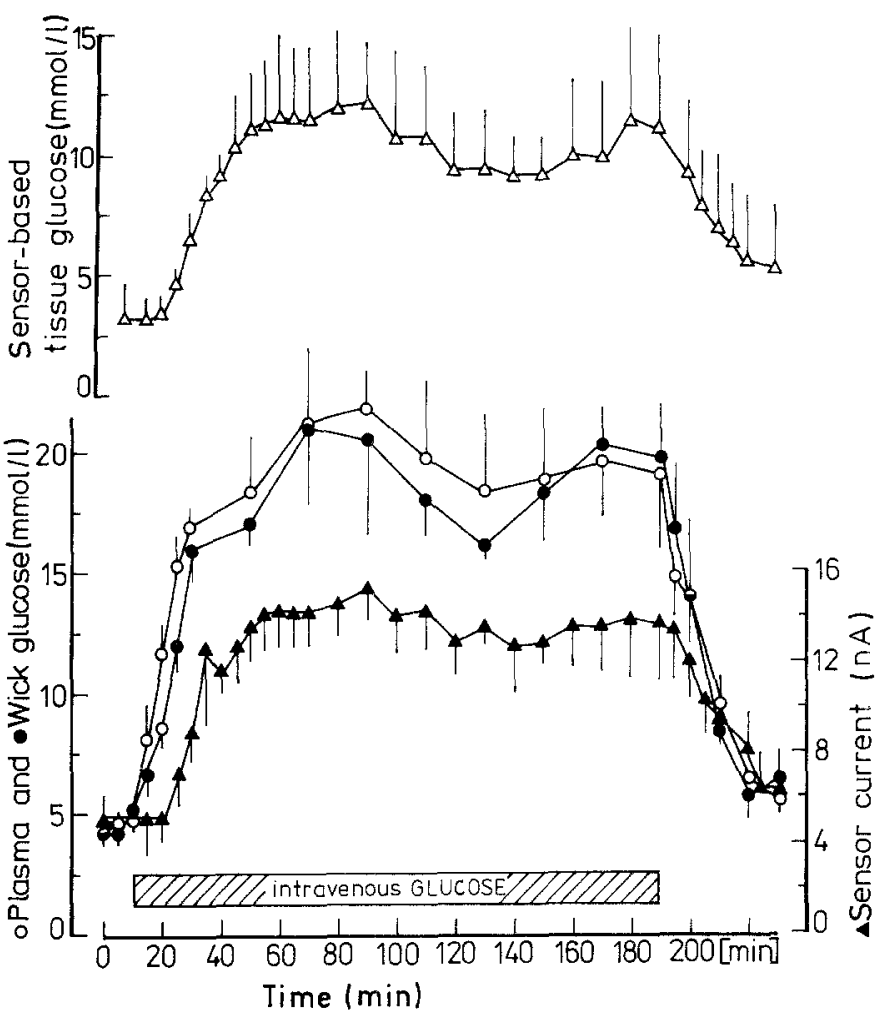

Fig.5. Same measurements and same symbols as in Figures 3 and 4 , during and after an intravenous infusion of $30 \mathrm{mg} \cdot \mathrm{kg}^{-1} \cdot \mathrm{min}^{-1} \mathrm{glu}-$ cose. $n=3$

diffusion coefficient is high in relation to that of all other substances of interest $[1,13,24]$. If constant conditions prevail in the microcirculation and in the convection, the time needed for equilibration between wick and interstitium depends on the concentration gradients and on the properties of the wick material. The only data available from the literature have shown an equilibration time of a least $60 \mathrm{~min}$ in albumin and onkotic pressure analyses from synthetic fibre-wicks [25]. In our experiments the equilibration could not be significantly accelerated by imbibing the threads with glucose-containing solutions before implantation (data not shown).

On the basis of an estimated intracellular potassium concentration of between 30 (skin and subcutaneous tissue) and $100 \mathrm{mmol} / 1$ (muscle), as calculated from published data $[26,27]$, the potassium concentration in the wick fluid indicates a significant but moderate destruction of cells due to wick insertion. From this, from the protein analyses which gave data close to the figures reported by Aukland et al. [19], and from the lack of any haemoglobin in the wick fluid it is concluded that the concentration measured in the wick samples is not substantially falsified by the admixture of blood or of intracellular constituents.

This is also supported by histological observations. Thus the wick technique may be recommended as a 
reference method for electrochemical and other types of subcutaneously implanted glucose sensors. It allows an actual in situ calibration of these sensors but unfortunately no direct zero checking. In addition, the investigation of kinetic properties of the interstitial glucose compartment is rendered possible. This is particularly important, since the influence of the sensors' delay factor on its in situ output has not been fully elucidated $[1,5]$. The wick system appears simple enough to solve this problem with respect to its application in feedback-controlled insulin infusion systems.

The data reported here show that under normo- or mildly hypo- or hyperglycaemic steady state conditions the subcutaneous interstitial glucose concentration is approximately identical to that in circulating blood. This is in agreement with reported findings on the physiology of microcirculation and the related filtration processes $[10,13]$. But it must be taken into consideration that under non-steady state conditions larger differences may appear between the two extracellular glucose compartments, i.e. between the intravascular and the interstitial one. On the basis of data obtained in thoracic duct lymph [13] the related time constant might be approximately $5 \mathrm{~min}$. With respect to a sensor- or wick dependent method, an additional time constant can be expected, i.e. the delay of the analytical system (see Materials and methods). Taken together, this may explain the difference in kinetics between circulating and interstitial glucose concentrations as measured either by the enzyme sensor or via the wick technique (Figs. 4 and 5).

There are, however, also significant differences between the latter two sets of data as long as the sensorrecorded values are based on vitro calibrations. This phenomenon which is analogous to the difference between sensor data and blood glucose [4-8], is probably based both on in vivo alterations in sensitivity of the sensors and on an insufficient microconvection and diffusion of glucose and oxygen to the sensor in situ [3, 22]. From the viewpoint of practical application, this may be overcome by calibration of the implanted sensor according to the directly measured interstitial glucose concentration which is essentially identical to the circulating glucose level when on steady state as shown here.

There were no local complications caused by the administration of wicks. In principle, this technique may also be used in man as described before in onkotic pressure studies $[25,28]$. In human use synthetic wick materials (e.g. polyamide or polyethylene silk) might be recommended because of their chemical inertness. Difficulties may, however, arise because of the smaller suction capacity of synthetic fibres in relation to cotton.

Taken together, the wick technique may be useful to obtain analytical reference samples of solutes contained in the interstitial fluid. It remains to be investigated whether in other tissues which behave differently in terms of architecture of microcirculation $[10,11]$ the level of interstitial glucose concentration and its kinetics behave in a similar fashion which would justify calibrating an implanted glucose sensor's signal simply on the basis of glycaemia [29].

Acknowledgements. This study was part of the research project HFR M 28 of the Ministry of Health of the German Democratic Republic. The secretarial assistence of Ms. G. Krüger and Ms. L. Brinkmann is gratefully acknowledged.

\section{References}

1. Gough DA, Leypoldt IK, Armour IC (1982) Progress toward a potentially implantable, enzyme-based glucose sensor. Diabetes Care 5: 190-198

2. Turner APF, Pickup IC (1985) Diabetes mellitus: biosensors for research and management. Biosensors 1: 85-115

3. Updike SJ, Shults M, Ekman S (1982) Implanting the glucose enzyme electrode: problems, progress, and alternative solutions. Diabetes Care 5: 207-212

4. Claremont DJ, Sambrook IE, Penton C, Pickup JC (1986) Subcutaneous implantation of a ferrocene-mediated glucose sensor in pigs. Diabetologia 29: 817-821

5. Clark jr LC, Duggen CA (1982) Implanted electroenzymatic glucose sensors. Diabetes Care 5: 174-180

6. Kessler M, Höper J, Volkholz H-J, Seiler D, Demling L (1984) A new glucose electrode for tissue measurements. Hepato-Gastroenterol 31: 285-288

7. Müller A, Abel P, Fischer U (1986) Kontinuierliche Messung der Glukosekonzentration im subkutanen Gewebe mit implantierbaren Enzymelektroden. Biomed Biochim Acta 45: 769-777

8. Shichiri M, Kawamori R, Yamasaki Y, Hakui N, Abe H (1982) Wearable artificial endocrine pancreas with needle-type glucose sensor. Lancet 2: 1129-1131

9. Özisik MN, Hilman R, Widmer F (1984) A model for the distribution and clearance of inert substances in subcutaneous tissue. Am J Physiol 246: R716-R720

10. Haraldsson B (1986) Physiological studies of macromolecular transport across capillary walls. Acta Physiol Scand 128 [Suppl]: 553

11. Rasio E (1982) The capillary barrier to circulating insulin. Diabetes Care 5: 158-161

12. Oberhardt BJ, Fogt EJ, Clemens AH (1982) Glucose sensor characteristics for miniaturized portable closed-loop insulin delivery: a step toward implantation. Diabetes Care 5: 213-217

13. Rasio EA, Hampers CL, Soeldner JS, Cahill GF (1987) Diffusion of glucose, insulin, and Evans blue protein into thoracic duct lymph of man. J Clin Invest 46: 903-910

14. Wolfson jr SK, Tokarsky JF, Yao SJ, Krupper MA (1982) Glucose concentration at possible sensor tissue implant sites. Diabetes Care 5: 162-166

15. Sembrowich WL, Martin RC, Hill HA, Knudson MB (1983) The dynamics of glucose concentration changes in potential body sites for glucose sensing. In: Sakamoto N, Alberti KGMM (eds) Current and future therapies with insulin. Proceeedings of the First International Symposium on Treatment of Diabetes mellitus. Nagoya, September 30 and October 1, 1982. Excerpta Medica, Amsterdam Oxford, pp 336-338

16. Hazel SJ, Thrall MAH, Severin GA, Lauerman LH, Lavach JD (1985) Laboratory evaluation of aqueous humor in the healthy dog, cat, horse, and cow. Am J Vet Res 46: 657-659

17. March WF, Rabinovitch B, Adams RL (1982) Noninvasive glucose monitoring of the aqueous humor of the eye: Part II. Animal studies and the scleral lens. Diabetes Care 5:259-265

18. Scholander PF, Hargens AR, Miller SL (1968) Negative pressure in the interstitial fluid of animals. Science 161: 321-328 
19. Aukland K, Fadnes HO (1973) Protein concentration of interstitial fluid collected from rat skin by a wick method. Acta Physiol Scand 88: $350-358$

20. Johnsen HM (1974) Measurement of colloid osmotic pressure of interstitial fluid. Acta Physiol Scand 91: 142-144

21. Freyse EJ, Hahn v. Dorsche H, Fischer U (1982) Low dose streptozotocin diabetes after partial pancreatectomy in dogs. Histological findings in a new type of experimental diabetes. Acta Biol Med Germ 4: 1203-1210

22. Abel P, Müller A, Fischer U (1984) Experience with an implantable glucose sensor as a prerequisite of an artificial beta cell. Biomed Biochim Acta 43: 577-584

23. Weetall $H$ (1970) Storage stability of water insoluble enzymes covalently coupled to organic and inorganic carriers. Biochim Biophys Acta 212: 1-7

24. Hillman RS (1982) Mass transport in the subcutaneous space. Swiss Federal Institute of Technology, Zürich Diss ETH No 7145, p $1-173$

25. Noddeland H (1982) Colloid osmotic pressure of human subcutaneous interstitial fluid sampled by nylon wicks: evaluation of the method. Scand J Clin Lab Invest 42: 123-130
26. Dickerson JWT, Widdowson EM (1960) Chemical changes in skeletal muscle during development. Biochem J 74: 247-257

27. Widdowson EM, Dickerson JWT (1960) The effect of growth and function on the chemical composition of soft tissues. Biochem J 77: 30-43

28. Fauchald P, Norsetn J, Jorvell J (1985) Transcapillary colloid osmotic gradient, plasma volume and interstitial fluid volume in long-term type 1 (insulin-dependent) diabetes. Diabetologia 28 : 269-273

29. Gough DA, Aisenberg S, Colton CK, Giner J, Soeldner JS (1977) The status of electrochemical sensors for in vivo glucose monitoring. Horm Metab Res 7 [Suppl-Ser]: 10-22

Received: 12 March 1987

accepted in revised form: 5 October 1987

Professor Uwe Fischer

Central Institute of Diabetes

"Gerhardt Katsch"

DDR-2201 Karlsburg

German Democratic Republic 